\title{
Autonomous marine hyperspectral radiometers for determining solar irradiances and aerosol optical properties
}

\author{
John Wood ${ }^{1}$, Tim J. Smyth ${ }^{2}$, and Victor Estellés ${ }^{3}$ \\ ${ }^{1}$ Peak Design Ltd, Sunnybank House, Wensley Rd, Winster, Derbys, DE4 2DH, UK \\ ${ }^{2}$ Plymouth Marine Laboratory (PML), Prospect Place, Plymouth, Devon, PL1 3DH, UK \\ ${ }^{3}$ Dept. Física de la Terra i Termodinàmica, Universitat de València, Burjassot, 46100, Spain \\ Correspondence to: Tim J. Smyth (tjsm@pml.ac.uk)
}

Received: 18 November 2016 - Discussion started: 26 January 2017

Revised: 4 April 2017 - Accepted: 18 April 2017 - Published: 9 May 2017

\begin{abstract}
We have developed two hyperspectral radiometer systems which require no moving parts, shade rings or motorised tracking, making them ideally suited for autonomous use in the inhospitable remote marine environment. Both systems are able to measure direct and diffuse hyperspectral irradiance in the wavelength range $350-1050 \mathrm{~nm}$ at $6 \mathrm{~nm}$ (Spectrometer 1) or $3.5 \mathrm{~nm}$ (Spectrometer 2) resolution. Marine field trials along a $100^{\circ}$ transect (between $50^{\circ} \mathrm{N}$ and $50^{\circ} \mathrm{S}$ ) of the Atlantic Ocean resulted in close agreement with existing commercially available instruments in measuring (1) photosynthetically available radiation (PAR), with both spectrometers giving regression slopes close to unity (Spectrometer 1 : 0.960; Spectrometer 2: 1.006) and $R^{2} \sim 0.96$; (2) irradiant energy, with $R^{2} \sim 0.98$ and a regression slope of 0.75 which can be accounted for by the difference in wavelength integration range; and (3) hyperspectral irradiance where the agreement on average was between 2 and $5 \%$. Two long duration land-based field campaigns of up to 18 months allowed both spectrometers to be well calibrated. This was also invaluable for empirically correcting for the wider field of view (FOV) of the spectrometers in comparison with the current generation of sun photometers $\left(\sim 7.5^{\circ}\right.$ compared with $\left.\sim 1^{\circ}\right)$. The need for this correction was also confirmed and independently quantified by atmospheric radiative transfer modelling and found to be a function of aerosol optical depth (AOD) and solar zenith angle. Once Spectrometer 2 was well calibrated and the FOV effect corrected for, the RMSE in retrievals of AOD when compared with a CIMEL sun photometer were reduced to $\sim 0.02-0.03$ with $R^{2}>0.95$ at wavelengths $440,500,670$ and $870 \mathrm{~nm}$. Corrections for the FOV as well as ship motion were applied to the data from the ma-
\end{abstract}

rine field trials. This resulted in $\mathrm{AOD}_{500 \mathrm{~nm}}$ ranging between 0.05 in the clear background marine aerosol regions and $\sim 0.5$ within the Saharan dust plume. The RMSE between the handheld Microtops sun photometer and Spectrometer 2 was between 0.047 and 0.057 with $R^{2}>0.94$.

\section{Introduction}

Tiny particles within the atmosphere, collectively known as aerosols, play a key role in the functioning of the Earth System as a whole. However, a great deal of uncertainty remains concerning precise and quantifiable mechanisms within that system. These mechanistic uncertainties generally fall into the broad categories of aerosol sources and subsequent sinks, aerosol transformational mechanisms (e.g. from aerosol to cloud condensation nuclei) and aerosol types. Aerosol type is determined by its source region, and in turn this determines its singular and integrated physical attributes. For example soot particles produced by natural or anthropogenic combustion are generally small in size, have a low single-scattering albedo and are subsequently highly absorbing in the optical region of the electromagnetic spectrum. Near the source regions these aerosols are small $(<1 \mu \mathrm{m})$ and high in number. In contrast, aerosols produced in the marine environment by breaking waves, wind-driven spume and bubble bursting are generally large (up to $10 \mu \mathrm{m}$ ) but relatively low in number. They have a high single-scattering albedo $(>0.95)$ and hence absorb a relatively small proportion of incoming solar radiation. Just from these two simple examples it can be seen that aerosol type will have a large bearing on the local, regional 
and global radiative balance and why a large uncertainty still exists in our understanding of precisely how aerosols impact Earth's climate as a whole.

During the past 20 years advances have been made in measuring aerosol optical properties over the terrestrial parts of the globe. These include the AERONET (Holben et al., 1998), SKYNET (Takamura and Nakajima, 2004) and ESR (Campanelli et al., 2012) networks which employ sunphotometric techniques to determine multi-spectral aerosol optical depth (AOD) and their physical characteristics (refractive index, single-scattering albedo, size distribution) by radiative inversion schemes (Nakajima et al., 1996; Dubovik and King, 2000). Although these networks are particularly densely populated in North America, eastern Asia and Europe, there is very little or non-existent coverage over the vast expanses of the global ocean. This is due in part to the difficulty in using a moving platform such as a ship to get an accurate fix on the position of the sun using a small, columnar field of view (FOV; typically $\sim 1^{\circ}$ ). Recent expansion by the AERONET network to cover the remote global ocean (Smirnov et al., 2009) has ameliorated this situation somewhat; however, the instruments typically used at sea rely upon handheld sun photometers, such as the Microtops (Morys et al., 2001), which by definition require a human operator. This generally limits the number of vessels, so-called "ships of opportunity", which carry such devices to scientific research expeditions. Ideally an autonomous instrument which can potentially be deployed on any ship or platform to cover the considerable gaps, spatial and temporal, in the ocean aerosol observing network needs to be developed.

The solar radiation measurement can be split into three components: the global horizontal irradiance, $I_{\mathrm{G}}$; direct normal irradiance, $I_{\mathrm{N}}$; and diffuse horizontal irradiance, $I_{\mathrm{D}}$. The current state-of-the-art solar radiation measurement (McArthur, 2005) uses a pyrheliometer on a solar tracker to measure $I_{\mathrm{N}}$ and pyranometers (one shaded by a trackermounted ball) to measure $I_{\mathrm{G}}$ and $I_{\mathrm{D}}$. However, such an instrument combination requires an initial high capital outlay and requires frequent and complex onsite maintenance. Other options include a pyranometer for $I_{\mathrm{G}}$ and a pyranometer with shade ring for $I_{\mathrm{D}}$, with $I_{\mathrm{N}}$ being calculated from these two components. The shade ring requires regular adjustment and a correction applied for the shaded part of the diffuse sky. Pertinent to this work, rotating shadowband radiometers which use a silicon photodiode detector and a motorised rotating shading ring to measure both $I_{\mathrm{G}}$ and $I_{\mathrm{D}}$ have been used in the marine environment to determine aerosol optical properties (Reynolds et al., 2001; Guzzi et al., 1985). Assuming a clear sky, and ideal cosine responsivity of the instrument input optics, the aerosol optical depth, $\tau_{\mathrm{a}}$, can then be calculated.

In this paper we describe a similar concept, but with the following important differences in construction: (1) use of a unique etched shadow design (Badosa et al., 2014), to remove the need for moving parts for splitting the irradiance into the global and diffuse components (2) use of hyperspectral radiometers to give finer spectral detail and hence aerosol optical characterisation. Difference (3) is particularly important in the harsh marine environment over prolonged periods of autonomous operation as salt spray can quickly seize moving parts as can freezing temperatures. We describe methods for accurate calibration of the instruments demonstrate their operational robustness on an Atlantic Meridional Transect cruise (AMT24; 22 September-1 November 2014) between the UK and the Falkland Islands, carry out an intercomparison between existing field-based instruments and highlight operational issues and propose solutions.

The structure of this paper is as follows. A methods section (Sect. 2) describing the theoretical basis (Sect. 2.1) and technological implementation (Sect. 2.2) of our approach together with the field-site setup (Sect. 2.3) and instrument calibration (Sect. 2.4). The results section (Sect. 3) focusses on correcting the measurements for orientation (Sect. 3.1) and field-of-view differences (Sect. 3.2) tackled using theoretical and land-based intercomparison campaigns, an intercomparison with co-located established marine radiometric instrumentation (Sect. 3.3) and finally an intercomparison with marine field measurements of aerosol optical depth corrected for orientation and field of view (Sect. 3.4).

\section{Method}

\subsection{Theory}

Devices to measure irradiance typically report raw values as voltages $(\mathrm{V})$, and thus

$\mathrm{V}_{\mathrm{G}}(\lambda)=\mathrm{V}_{\mathrm{H}}(\lambda)+\mathrm{V}_{\mathrm{D}}(\lambda)$

where $\lambda$ is wavelength, $\mathrm{G}$ is global, $\mathrm{H}$ is horizontal direct, and $\mathrm{D}$ is diffuse. See Table 1 for a glossary of symbols and definitions. The volts directed onto the horizontal plane, $\mathrm{V}_{\mathrm{H}}(\lambda)$, are normalised by the solar zenith angle $\left(\theta_{\mathrm{s}}\right)$ using

$\mathrm{V}_{\mathrm{N}}(\lambda)=\mathrm{V}_{\mathrm{H}}(\lambda) \sec \theta_{\mathrm{s}}$

The instrument can be calibrated against known standard instruments in the laboratory or in the field. It is also necessary to carry out a Langley calibration (Adler-Golden and Slusser, 2007) of the instrument during clear and stable atmospheric conditions over the course of a day using Beer's Law to obtain the top-of-atmosphere voltage, $\mathrm{V}_{T}(\lambda)$. This can be represented as

$\mathrm{V}_{\mathrm{N}}(\lambda)=\mathrm{V}_{\mathrm{T}}(\lambda) \exp (-\tau(\lambda) m)$,

where $\tau(\lambda)$ is the optical depth and $m$ is the atmospheric airmass, in this paper defined as

$m=\frac{1}{\cos \theta_{\mathrm{s}}+a\left(b-\theta_{\mathrm{s}}\right)^{-c}}$. 
Table 1. Glossary of terms and symbols.

\begin{tabular}{|c|c|c|}
\hline Symbol & Description & SI units \\
\hline$I_{\mathrm{G}}(\lambda)$ & (Spectral) Global horizontal irradiance (GHI) & $\mathrm{Wm}^{-2}\left(\mathrm{~nm}^{-1}\right)$ \\
\hline $\mathrm{V}_{\mathrm{G}}(\lambda)$ & (Spectral) GHI measured as a voltage & $\mathrm{V}$ \\
\hline$I_{\mathrm{N}}(\lambda)$ & (Spectral) Direct normal irradiance (DNI) & $\mathrm{Wm}^{-2}\left(\mathrm{~nm}^{-1}\right)$ \\
\hline $\mathrm{V}_{\mathrm{N}}(\lambda)$ & (Spectral) DNI measured as a voltage & $\mathrm{V}$ \\
\hline$I_{\mathrm{D}}(\lambda)$ & (Spectral) Diffuse horizontal irradiance (DHI) & $\mathrm{Wm}^{-2}\left(\mathrm{~nm}^{-1}\right)$ \\
\hline $\mathrm{V}_{\mathrm{D}}(\lambda)$ & (Spectral) DHI measured as a voltage & $\mathrm{V}$ \\
\hline$I_{\mathrm{H}}(\lambda)$ & (Spectral) Direct beam horizontal irradiance (BHI) & $\mathrm{Wm}^{-2}\left(\mathrm{~nm}^{-1}\right)$ \\
\hline $\mathrm{V}_{\mathrm{H}}(\lambda)$ & (Spectral) BHI measured as a voltage & $\mathrm{V}$ \\
\hline $\mathrm{V}_{\mathrm{T}}(\lambda)$ & (Spectral) Top-of-atmosphere (TOA) voltage & $\mathrm{V}$ \\
\hline $\mathrm{V}_{0 \mathrm{~T}}(\lambda)$ & (Spectral) TOA voltage corrected for elliptical Earth orbit & $\mathrm{V}$ \\
\hline$I_{\max }(\lambda)$ & (Spectral) Maximum irradiance & $\mathrm{Wm}^{-2}\left(\mathrm{~nm}^{-1}\right)$ \\
\hline$I_{\min }(\lambda)$ & (Spectral) Minimum irradiance & $\mathrm{Wm}^{-2}\left(\mathrm{~nm}^{-1}\right)$ \\
\hline$\theta_{\mathrm{rs}}$ & Relative solar angle (angle of incidence to plane of detector) & Radians \\
\hline$\theta_{\mathrm{S}}$ & Solar zenith angle & Radians \\
\hline$\alpha_{\mathrm{sf}}$ & Surface zenith angle & Radians \\
\hline$\varphi_{\mathrm{s}}$ & Solar azimuth angle & Radians \\
\hline$\beta_{\mathrm{sf}}$ & Surface azimuth angle & Radians \\
\hline$\tau_{\mathrm{a}}(\lambda)$ & Aerosol optical depth & Unitless \\
\hline$\tau_{\mathrm{R}}(\lambda)$ & Rayleigh optical depth & Unitless \\
\hline$\tau_{\mathrm{O}}(\lambda)$ & Ozone optical depth & Unitless \\
\hline FWHM & Full width at half maximum & $\mathrm{nm}$ \\
\hline
\end{tabular}

In Eq. (4) the constants a, b and c are set to 0.50572, 96.07995 and 1.6364 respectively (Kasten and Young, 1989). To account for the elliptical nature of Earth's orbit, the following expression is used:

$\mathrm{V}_{0 \mathrm{~T}}(\lambda)=\mathrm{V}_{\mathrm{T}}(\lambda) r^{2}$

where

$r=(1-\varepsilon \cos (a[J-4]))$

with $J$ being the serial day of the year, $\varepsilon$ being the eccentricity of the orbit (0.01673) and $a=2 \pi / 365.25$. Expanding Eq. (3) into the component parts of the optical depth, Rayleigh (R), aerosol (a) and atmospheric trace gases (g) results in

$\mathrm{V}_{\mathrm{N}}(\lambda)=\frac{\mathrm{V}_{0 \mathrm{~T}}(\lambda)}{r^{2}} \exp \left(-\left(\tau_{\mathrm{R}}(\lambda)+\tau_{\mathrm{a}}(\lambda)+\tau_{\mathrm{g}}(\lambda)\right) m\right)$

The trace gas component (such as ozone, nitrous oxide, water vapour) can be derived from measurements or distribution climatologies in conjunction with models such as SMARTS2 (Simple Model of the Atmospheric Radiative Transfer of Sunshine 2; Gueymard, 2001); the Rayleigh component can be calculated from (Reynolds et al., 2001)

$\tau_{\mathrm{R}}(\lambda)=\frac{P}{P_{0}}\left(a_{1} \lambda^{4}+a_{2} \lambda^{2}+a_{3}+a_{4} \lambda^{-2}\right)^{-1}$,

where $P$ is the atmospheric pressure (mbar), $P_{0}=1013.25$ mbar; $\quad a_{1}=117.2594 ; \quad a_{2}=-1.3215$;

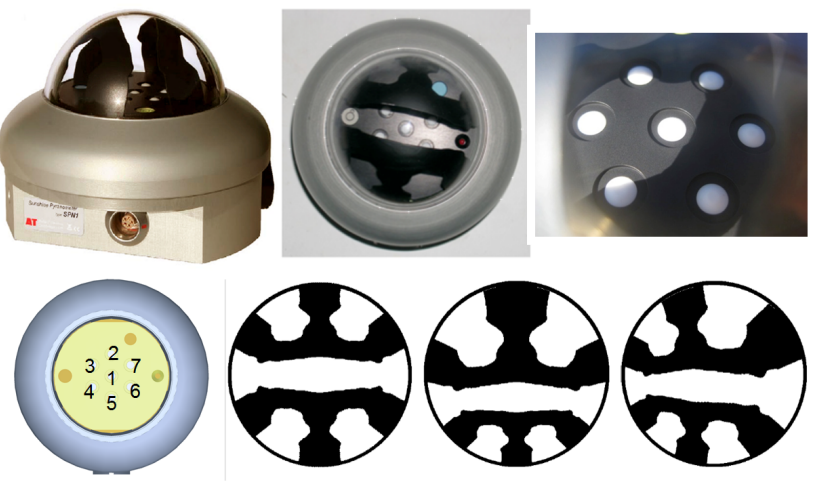

Figure 1. Taken from Badosa et al. (2014). Top row: left photo shows the side view of the SPN1 and the middle is a photograph from directly above the unit; the photo on the right demonstrates the shadow pattern on the seven sensors under direct sunshine conditions. Bottom row: left gives SPN1 detector numbering; sky seen under shade patterns as seen for sensor 1 (left), sensors 2 and 5 (middle), and sensors 3, 4, 6 and 7 (right).

$a_{3}=0.00032073 ;$ and $a_{4}=-0.000076842$. Rearranging Eq. (7) allows the aerosol optical depth to be calculated for each individual optical wavelength. The trace gas components are not corrected for in this study as we have chosen to compare against existing instrumentation which operate within atmospheric windows where gas absorption is negligible or very small. 
This analysis is presented in terms of voltages with arbitrary scaling. After calibration, the spectrometer system gives outputs in radiometric units, so the top-of-atmosphere values give an extra-terrestrial spectrum which should match the SMARTS2 model. The SMARTS2 spectrum is used as reference in subsequent AOD calculations.

\subsection{Technological implementation}

\subsubsection{SPN1 Radiometer}

The SPN1 (Wood, 1999) is a broadband radiometer without moving parts, shade rings or motorised tracking that measures $I_{\mathrm{G}}$ and $I_{\mathrm{D}}$ broadband short-wave irradiance (from 400 to $2700 \mathrm{~nm}$ ) expressed in $\mathrm{Wm}^{-2}$. The SPN1 was designed with seven thermopiles: six sensors placed on a hexagonal grid, one sensor at the centre, under a complex static shading mask (see Fig. 1) in such a way to ensure that, at any time, for any location (1) at least one sensor is always exposed to the full solar beam, (2) at least one sensor is always completely shaded, and (3) the solid angle of the shading mask is equal to $\pi$, thus corresponding to half of the hemispherical solid angle.

Under the assumption of isotropic diffuse sky radiance, the third property related to the shading mask implies that all sensors receive equal amounts $(50 \%)$ of diffuse irradiance from the rest of the sky hemisphere. It can therefore be seen that at any instant, the minimum signal $\left(I_{\min }\right)$ measured among the seven sensors is the shaded sensor, which measures half the $I_{\mathrm{D}}$, and the maximum signal $\left(I_{\max }\right)$ from among the seven sensors is fully exposed to the solar beam, and therefore measures the $I_{\mathrm{H}}$ plus half the $I_{\mathrm{D}}$. From this the following relationships can be formed:

$I_{\mathrm{D}}=2 I_{\min }$,

$I_{\mathrm{H}}=\left(I_{\max }-I_{\min }\right)$,

$I_{\mathrm{G}}=I_{\mathrm{H}}+I_{\mathrm{D}}=I_{\max }+I_{\min }$.

By calculating the (relative) solar zenith angle $\left(\theta_{\mathrm{rs}}\right)$ using the known time and geographical position, $I_{\mathrm{N}}$ can be derived as

$I_{\mathrm{N}}=I_{\mathrm{H}} \sec \left(\theta_{\mathrm{rs}}\right)$.

For a detailed study of the performance of the SPN1, the reader is referred to Badosa et al. (2014).

\subsubsection{Spectrometers based on the SPN1}

In this study, the broadband detectors of the SPN1 have been replaced by spectrometers to give hyperspectral measurements of $I_{\mathrm{G}}(\lambda), I_{\mathrm{D}}(\lambda)$ and $I_{\mathrm{N}}(\lambda)$ over the range 350 $1050 \mathrm{~nm}$. Light is collected from behind the diffuser elements of the SPN1 optical head and routed to a spectrometer via an optical fibre. In order to evaluate the various tradeoffs between cost, speed of measurement and consistency of measurement, prototypes of two different configurations were constructed (see Fig. 2).

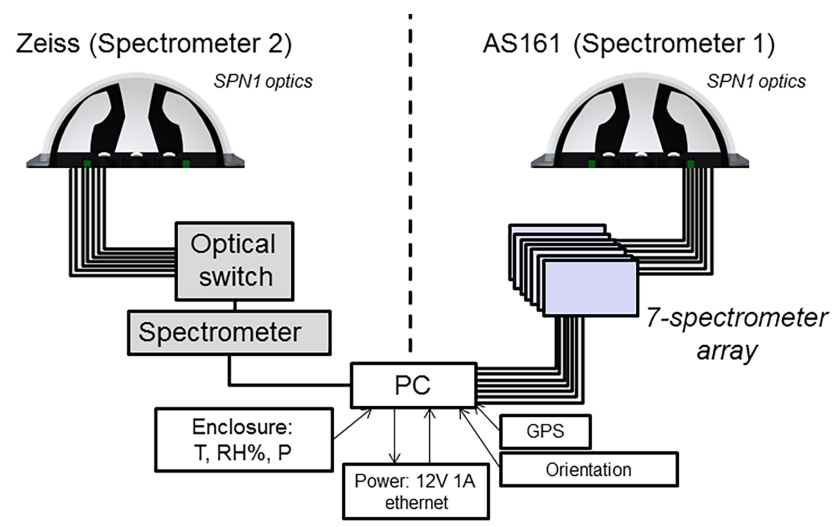

Figure 2. System diagram for the two spectrometer configurations. Elements in white are common to both configurations, although each have their own separate PC, GPS, etc. The main configurational difference is that AS161 (Spectrometer 1) contains seven spectrometers, whereas Zeiss (Spectrometer 2) contains only one which is connected to the seven optical channels via an optical switch. The PC enclosure temperature $(T)$, relative humidity $(\mathrm{RH})$ and atmospheric pressure $(P)$ is monitored.

\subsubsection{Spectrometer system 1 - AS161}

In this configuration, the seven optical fibres were each routed directly to one of seven low-cost optical benches manufactured by Avantes and controlled by the Avantes AS161 control board. These optical benches had 128 pixel detectors giving a pixel resolution of around $6 \mathrm{~nm}$ across the range $350-1050 \mathrm{~nm}$, at a spectral resolution $(\Delta \lambda \mathrm{FWHM})$ of $13 \mathrm{~nm}$, with $<0.2 \%$ stray light. The advantage of this configuration is that all seven optical channels can be read in parallel in a short time $(<1 \mathrm{~s})$, therefore removing many of the potential artefacts due to making measurements on a moving platform. The main disadvantages are that (1) a cheaper spectrometer is required, (2) it is more difficult to maintain a close matching between spectrometer calibrations and (3) the wavelengths corresponding to each pixel are different for each measurement channel. Note that Spectrometer 1 developed an electronics fault towards the end of the AMT cruise, so a shorter period of comparison results is available than for Spectrometer 2.

\subsubsection{Spectrometer system 2 - Zeiss}

In this configuration, the seven optical fibres are taken via a fibre-optic multiplexer to a single Zeiss MMS1 spectrometer. This has a 256-pixel detector, giving a pixel resolution of around $3.5 \mathrm{~nm}$ across the range $350-1050 \mathrm{~nm}$, at a spectral resolution $(\Delta \lambda \mathrm{FWHM})$ of $10 \mathrm{~nm}$. The advantage of this configuration is that Zeiss is a very stable spectrometer $(0.3 \mathrm{~nm}$ accuracy) over a wide range of temperatures $\left(<0.01 \mathrm{~nm} \mathrm{~K}^{-1}\right)$, with a high sensitivity $\left(10^{3} \mathrm{Vs}^{-1}\right)$ and low stray light characteristics $(<0.8 \%)$. The MMS1 temperature coefficient ranges from $-0.2 \% \mathrm{~K}^{-1}$ in the $350-800 \mathrm{~nm}$ 
range, rising to $0.6 \% \mathrm{~K}^{-1}$ at $1000 \mathrm{~nm}$, measured over -20 to $+60^{\circ} \mathrm{C}$. All seven optical channels are measured at the same sensitivity and set of wavelengths. The primary disadvantage of this configuration is that the seven optical channels are measured sequentially over a period of 20 s in total. This means that irradiance variations due to cloud or movement occurring during the measurement period will compromise the accuracy of the overall measurement.

\subsubsection{Control electronics and software}

Both spectrometer systems are controlled by an embedded $\mathrm{PC}$ running Windows XP. There are also additional sensors to measure GPS position and time, atmospheric pressure, temperature and humidity within the enclosure. A heading, pitch and roll sensor was also included. The control software is responsible for reading the spectrometer values, sequencing the switch, and combining the values into calibrated measurements of $I_{\mathrm{G}}(\lambda)$ and $I_{\mathrm{D}}(\lambda)$, and recording these at the appropriate times ( 1 min intervals), along with readings of the additional environmental sensors. The system is controlled via an ethernet connection. Each spectrometer system required a $12 \mathrm{~V}$ power supply capable of $1 \mathrm{~A}$ peak draw; all these components were packaged in a weatherproof enclosure.

\subsubsection{GPS position and time}

Both spectrometers were fitted with GPS receivers, and the GPS time and position recorded throughout the cruise. The spectrometers were referenced to their own embedded PC clocks, and these showed drifts of several minutes over the duration of the 6-week cruise. By referring all the readings to GPS time, it was possible to compare the various datasets using a consistent time base.

\subsubsection{Data sampling and recording}

The two spectrometer configurations required slightly different sampling and recording strategies.

\section{Spectrometer 1 - AS161}

In this spectrometer, all seven measurement channels are read in parallel over a $500 \mathrm{~ms}$ time span. To compensate for wave motion, a burst of 10 readings is taken at 1 per second. The average of these 10 readings is used for subsequent calculations, although the individual burst readings are available if necessary. A burst of readings is repeated every minute.

\section{Spectrometer 2 - Zeiss}

In this spectrometer, the seven measurement channels are measured sequentially. Each channel takes approximately $3 \mathrm{~s}$, so a full measurement takes $\sim 20 \mathrm{~s}$. At each channel reading, the SPN1 irradiance is also measured, along with orientation values from the VectorNav sensor. These values are

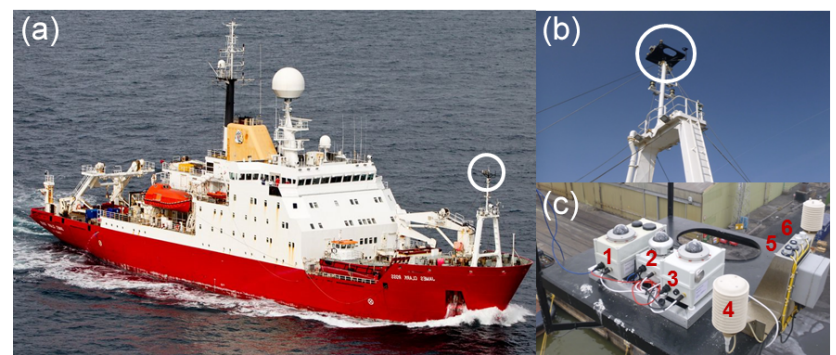

Figure 3. (a) RRS James Clark Ross showing the position of the foremast and instrument platform (circled). (b) The instrument platform (circled) viewed from below on the main deck. (c) Instruments in situ on the platform. (1) Spectrometer 1 - AS161; (2) SPN1; (3) Spectrometer 2 - Zeiss; (4) meteorological instrument solar radiation shield; (5) Kipp \& Zonen PAR sensors (x2); (6) Kipp \& Zonen pyranometers (x2).

used to improve the measurements by correcting for tilt during subsequent analysis.

\subsection{Description of measurement sites and setup}

Both spectrometer systems were deployed on the Atlantic Meridional Transect expedition cruise, which sailed between the UK and the Falkland Islands on board the RRS James Clark Ross, from 22 September to 4 November 2014. The spectrometers were mounted on the top of the foremast of the British Antarctic Survey research ship RRS James Clark Ross on a dedicated instrument platform (Fig. 3). Access was only possible via the ship's crane and hoist when in port at the beginning and end of the cruise, so once installed there was no further opportunity for modifications or maintenance. The spectrometers were both mounted in IP67 weatherproof enclosures and fitted with desiccant packs. The heat generated by the electronics increased the internal temperature by around $10-15^{\circ} \mathrm{C}$ above the ambient, and this helped to keep the internal humidity to less than $30 \%$ during the cruise. An SPN1 radiometer was also mounted alongside the two spectrometers to give a broadband irradiance reference. The instruments were powered by a $12 \mathrm{~V}$ power cable, and communications were provided by an ethernet cable, both routed up the mast. The performance of the spectrometers was monitored throughout the cruise, remotely from inside the ship, via the ethernet connection. A Satlantic hyperspectral radiometer, Kipp \& Zonen photosynthetically available radiation (PAR) sensors, and Kipp \& Zonen pyranometers were also mounted on the instrument platform throughout the cruise.

The AMT encounters a wide variety of aerosol optical properties, from the low $\tau_{\mathrm{a}}$ background marine aerosols of the South Atlantic Ocean (Lin et al., 2016) to the higher turbidities to the west of Africa under the influence of airborne desert dust (Caquineau et al., 2002; Baker et al., 2006). Values of $\tau_{\mathrm{a}}(\lambda)$ were determined using a manually oper- 
ated handheld Microtops II instrument at 380, 440, 500, 675, 870 and $1020 \mathrm{~nm}$ and the data processed to level 2.0 (cloud screened, visually inspected and post-cruise calibrated) using the protocols adopted by the AERONET Maritime Aerosol Network (Smirnov et al., 2009). The estimated absolute uncertainty in individual level 2 observations does not exceed 0.02 in any of the spectral channels.

Prior to the AMT cruise, Spectrometer 1 (AS161) was deployed on the roof of the Plymouth Marine Laboratory (Plymouth, UK: $50^{\circ} 21.95^{\prime} \mathrm{N}, 4^{\circ} 8.85^{\prime} \mathrm{W}$ ), in close proximity to the established ESR network (Campanelli et al., 2012) PREDE POM01-L sun photometer, between 14 July and 8 September 2014. The site is generally characterised by aerosols of a marine origin (Estellés et al., 2012). Aerosol optical properties, including $\tau_{\mathrm{a}}(\lambda)$, were determined from the POM01-L measurements at 400, 500, 670, 870 and $1020 \mathrm{~nm}$ using the inversion technique of Nakajima et al. (1996).

Following the AMT cruise, Spectrometer 2 (Zeiss) was deployed at the Burjassot site (Valencia, Spain: $39^{\circ} 30.58^{\prime} \mathrm{N}, 0^{\circ} 25.08^{\prime} \mathrm{W}$ ), which has both ESR-POM01-L and AERONET-CIMEL CE318 sun photometers, between January 2015 and June 2016. The site is affected by many different aerosol types, including urban, marine (Mediterranean) and Saharan dust (Estellés et al., 2007). Values of $\tau_{\mathrm{a}}(\lambda)$ were determined using the CIMEL CE318 measurements at 440,500, 670, 870 and $1020 \mathrm{~nm}$, processed by AERONET algorithm version 2 (level 2 until April 2015 and level 1.5 from April 2015 to June 2016).

The values of $\tau_{\mathrm{a}}(\lambda)$ calculated using the two spectrometers were compared against the coincidental land-based sun photometers (PML, Burjassot) and marine sun-photometer (AMT) deployments. The spectrometer hyperspectral values were integrated to give similar bandwidths $(\sim 10 \mathrm{~nm})$ to the sun photometers for AOD calculations. To give an accurate comparison, all the different instruments were referred to GPS time. The spectrometer datasets were filtered to select stable conditions in which $\mathrm{AOD}_{500 \mathrm{~nm}}$ varied by less than 0.05 over a $5 \mathrm{~min}$ window, as measured by the spectrometer. The spectrometer filtered $1 \mathrm{~min}$ readings were interpolated to the time of the comparison instrument reading.

\subsection{Calibration and traceability}

There are two requirements for calibration of this spectrometer system. Firstly, the seven individual channels should have an identical response to incident light. Secondly the response should be matched to the absolute irradiance scale across the whole spectrum. To achieve this, the spectrometers were first calibrated using a $300 \mathrm{~mm}$ diameter integrating sphere illuminated by a halogen lamp to give a uniform diffuse irradiance across all seven sensors. The irradiance at the integrating sphere port was calibrated to an Ocean Optics LS-1 calibration lamp to give an approximately correct calibration for each sensor. In particular, because the halogen lamp has a smoothly varying spectral distribution, the relative values

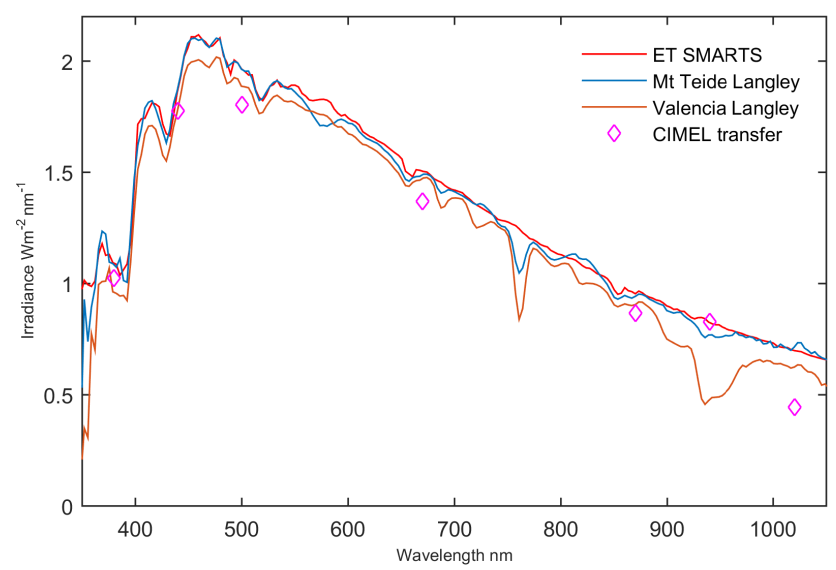

Figure 4. Calibration curve for Spectrometer 2 (Zeiss). Extraterrestrial spectrum as predicted from the SMARTS2 model, Langley calibrations on Mt Teide (Tenerife), Valencia (Spain) and from calibration transfer from the CIMEL sun photometer at Valencia.

will be correct over moderate wavelength intervals, even if the absolute scaling is incorrect. Following this, the spectral calibration was adjusted using the Langley method on $\mathrm{Mt}$ Teide, Tenerife ( $2300 \mathrm{~m}$, near the base of the teleferico). The calibration was adjusted smoothly across the whole spectrum using the Langley values outside the gas absorption bands to give a final absolute calibration. The instrument outputs were calibrated to radiometric units, so the Langley calculated TOA values should match the SMARTS2 extraterrestrial spectrum outside the of gas absorption bands.

After the AMT24 cruise, Spectrometer 2 (Zeiss) was colocated with a CIMEL sun photometer in Burjassot for 18 months. Its calibration was further checked using the Langley method during selected clear-sky periods and also by a direct comparison with the CIMEL $I_{\mathrm{N}}(\lambda)$ measurements at the specific CIMEL wavelengths. Figure 4 shows how these different methods compare, by plotting the extra-terrestrial irradiance values they predict. It is evident that the Langley plot performed at Mt Teide closely matches the SMARTS2 spectrum due to the site pristine conditions, except for the gas absorption bands where the Langley method cannot be applied correctly. The effect of the gases in these bands is even clearer for the Langley extra-terrestrial spectrum obtained at Valencia, as the water vapour amount is higher at sea level. In any case the absorption bands will not be used for deriving the aerosol optical depth.

\section{Results}

\subsection{Correcting data for ship motion}

Both spectrometer systems were fitted with a VectorNav VN100 inertial orientation sensor, containing three-axis sensors for each of linear acceleration, angular acceleration and 
magnetic field. From these measurements, the sensor calculates values of yaw (heading), pitch and roll. These measurements allowed the spectral measurements to be corrected for the tilt of the instruments away from the horizontal. Following analysis of the orientation values after the AMT cruise, the VectorNav yaw values showed significant drift compared to the yaw values calculated from both the GPS track and the ship's heading record. This was due magnetic interference from the ship's ironwork, which had not been compensated for when the spectrometers were installed. However, the pitch and roll values could still be used in combination with yaw values either taken from the ship's data records after the cruise or calculated from the GPS track values.

Long et al. (2010) demonstrated a method for correcting pyranometer measurements on an aircraft using SPN1 measurements. We have used a similar technique to correct both the SPN1 and Spectrometer 2 values in this study. In correcting the Spectrometer 2 values, it is assumed that the diffuse part of the incident light is unaffected by tilt. The diffuse value is calculated from the minimum of the seven channels. This is subtracted from all the other channels to give the direct beam part of the reading on the instrument plane $\left(I_{\text {Hmeas }}\right)$. The direct beam part is then corrected according to the known position of the sun, and the angle of incidence on the tilted instrument plane is calculated from the orientation values.

$I_{\text {Hcorr }}=\frac{I_{\text {Hmeas }}}{\cos \theta_{\mathrm{rs}}} \cos \theta_{\mathrm{s}}$,

where

$\cos \theta_{\mathrm{rs}}=\cos \theta_{\mathrm{s}} \cos \alpha_{\mathrm{sf}}+\sin \theta_{\mathrm{s}} \sin \alpha_{\mathrm{sf}} \cos \left(\phi_{\mathrm{s}}-\beta_{\mathrm{sf}}\right)$.

See Table 1 for definition of the various angles. The seven channels are then recalculated from the $I_{\min }+I_{\mathrm{Hcorr}}$ and used to calculate the corrected $I_{\mathrm{G}}, I_{\mathrm{D}}$ and $I_{\mathrm{N}}$ using Eqs. (9)-(11). This correction is also applied to the SPN1 values.

There are two contributions to irradiance variation during the reading period - variations in the overall irradiance values (e.g. variable cloud cover, particularly obscuring the solar disc) and variations due to tilt of the ship. This correction strategy will correct for the ship's movement but not variations in light levels during the reading period.

The repeated SPN1 readings give the best indication of the effectiveness of the tilt correction strategy. Detailed results are shown for the afternoon of 30 October 2014 (Fig. 5), as this was a day with relatively high pitch and roll values (peak amplitude around $5^{\circ}$ ) and also a relatively sunny day. The time-series plot for the day shows the $I_{\mathrm{N}}$ (green), $I_{\mathrm{G}}$ (red) and $I_{\mathrm{D}}$ (blue) values as measured directly and the corrected $I_{\mathrm{N}}$ and $I_{\mathrm{G}}$ (darker colours). It is clear that the corrected values show a large improvement for the stable clear-sky periods (e.g. 17:30 to 19:30), with the standard deviation in the readings of $I_{\mathrm{N}}$ being reduced by up to a factor of four. Taking an average of the burst of SPN1 readings gives an even
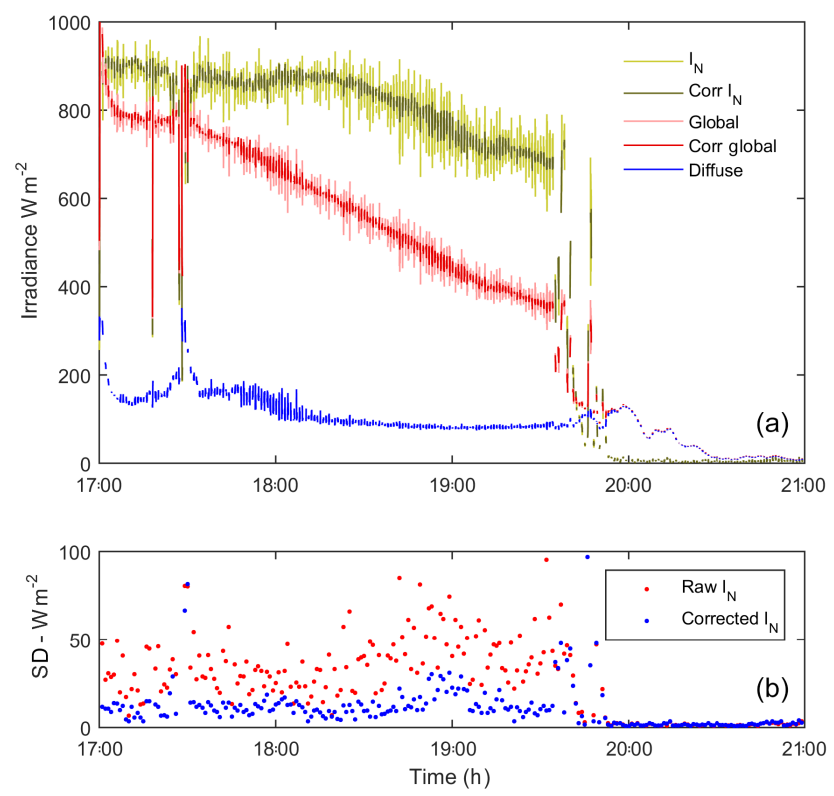

Figure 5. SPN1 tilt correction illustration data for 30 October 2014. (a) Uncorrected $I_{\mathrm{N}}$ (light green) and corrected $I_{\mathrm{N}}$ (dark green); uncorrected and corrected $I_{\mathrm{G}}$ (light and dark red) together with $I_{\mathrm{D}}$ (blue). (b) Standard deviation for uncorrected $I_{\mathrm{N}}$ (red) and corrected $I_{\mathrm{N}}$ (blue).

smoother trace, but this option is not possible using Spectrometer 2 (Zeiss) because of the time taken to observe the entire spectrum $(20 \mathrm{~s})$.

Figure 5 summarises this improvement by showing the standard deviation of the eight measurements within each 1 min burst. During periods of broken cloud, variability is high. This is caused by large light level variations due to cloud edges during the 20s burst. During clear-sky periods (e.g. 17:30 to 19:30) the burst variability is reduced to 20 $30 \%$ of the uncorrected value by implementing the correction procedure. During wholly overcast periods (e.g. 20:00 to 21:00) the variability is obviously minimised. This correction procedure is applied to all readings for Spectrometer 2 (Zeiss) during the AMT24 cruise. As a direct consequence of this, the subsequently calculated AOD values show less variability during stable periods.

\subsection{Correcting data for different field-of-view angles}

Prior to the AMT24 cruise, Spectrometer 1 (AS161) was mounted on the roof at PML in Plymouth, adjacent to a PREDE POM-01 sun photometer, between 14 July and 8 September 2014. The AOD intercomparison (Fig. 6) between the two instrument datasets results in a high $R^{2}$ (ranging between 0.768 at $870 \mathrm{~nm}$ and 0.940 at $500 \mathrm{~nm}$ ) and an RMSE of between $0.040(675 \mathrm{~nm})$ and $0.075(400 \mathrm{~nm})$. This is similar to differences found between LICOR LI1800 spectrometers (Estellés et al., 2006). The $400 \mathrm{~nm}$ channel performance was somewhat worse than the other wavelengths using the RMSE 


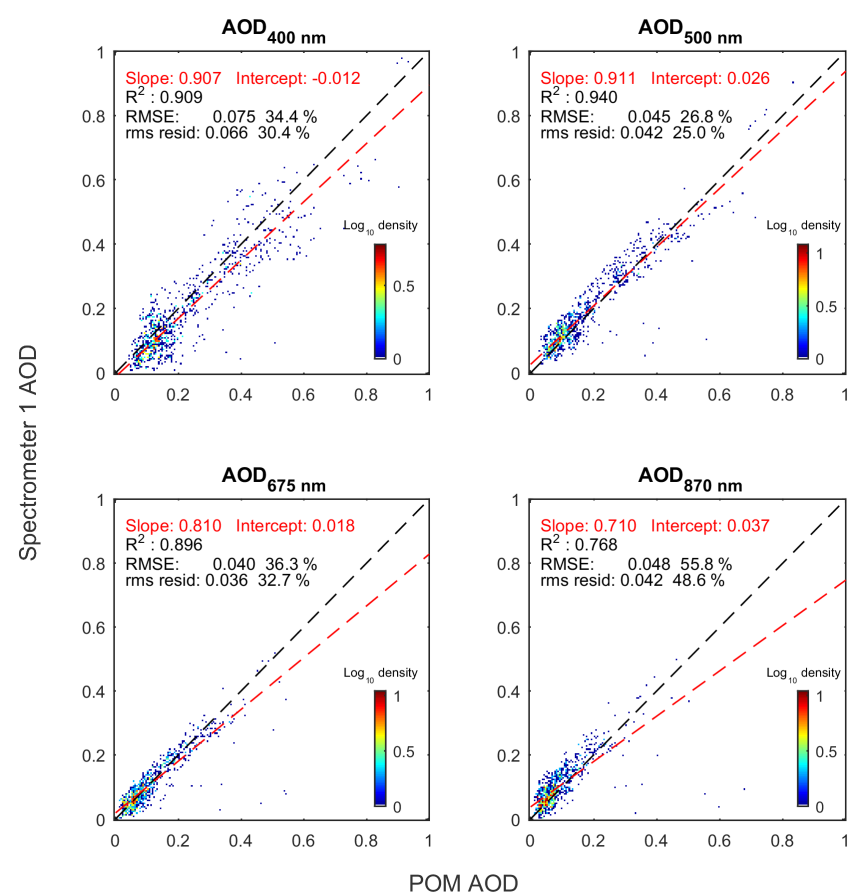

Figure 6. Spectrometer 1 (AS161) AOD results compared with PREDE POM-01 on the roof of Plymouth Marine Laboratory, 14 July-8 September 2014. Spectrometer readings restricted to clear stable periods. These are log density plots: red points represent around 100 data points, whereas the blue points only represent a single data point. No further corrections were applied.

metric (0.0705). This is due largely to the diminishing sensitivity of the AS161 spectrometer at $400 \mathrm{~nm}$ and below. There are also noticeable changes in the regression slope with the wavelength in Fig. 6, this varying between $0.911(500 \mathrm{~nm})$ and $0.710(870 \mathrm{~nm})$. The intercept value also varies between $-0.012(400 \mathrm{~nm})$ and $0.037(870 \mathrm{~nm})$. Some of the outliers shown in Fig. 6 are likely to be caused by imperfect cloud screening of data from either or both sensors.

Following the AMT24 cruise, Spectrometer 2 (Zeiss) was co-located with a CIMEL sun photometer at the Burjassot site, between January 2015 and June 2016. These land-based results (Fig. 7) show that there is a consistent relationship between the spectrometer and sun-photometer-derived AOD measurements. The regression slope varies between 0.786 at $440 \mathrm{~nm}$ and 0.687 at $870 \mathrm{~nm}$ (decreasing slope with increasing wavelength), with a broad decrease in the intercept from $\sim 0.03$ to 0.02 (decreasing intercept with increasing wavelength). There is also a reduction in the residuals from 0.029 at $440 \mathrm{~nm}$ to 0.015 at $870 \mathrm{~nm}$. The value of $R^{2}$ remains largely unchanged at around 0.95 . A notable feature of both Figs. 6 and 7 is the significant, but consistent, deviation away from the $1: 1$ line when comparing the different instrument retrievals of AOD. One possible source of this behaviour is thought to be the wider field of view of the SPN1 optical design. This is typically between 5 and $10^{\circ}$, whereas

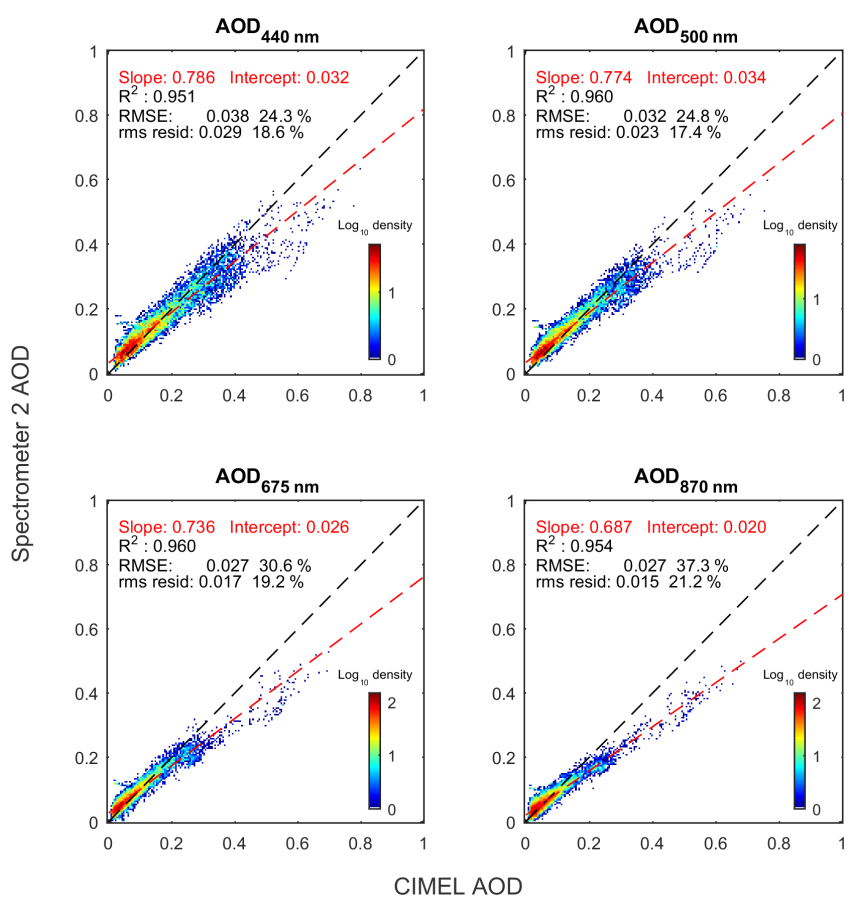

Figure 7. Spectrometer 2 (Zeiss) AOD results compared with CIMEL sun photometer at Burjassot, January 2015-July 2016. These are log density plots: red points represent around 100 data points, whereas the blue points only represent a single data point. No further corrections were applied.

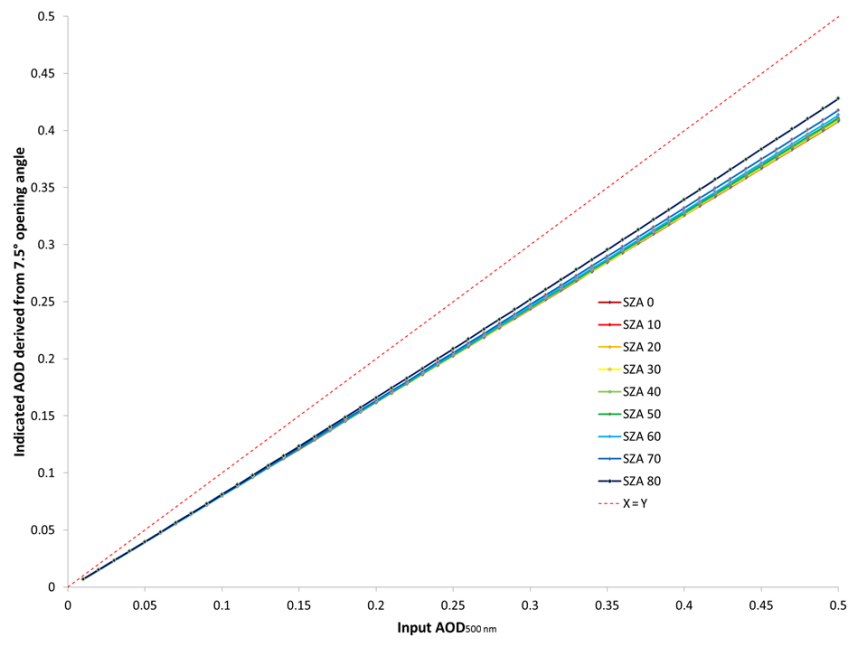

Figure 8. Theoretical AOD computed from measured $I_{\mathrm{N}}$ according to the SMARTS2 (Gueymard, 2001) model, when using a $7.5^{\circ} \mathrm{FOV}$ detector. The different coloured lines represent different solar zenith angles. Indicated AOD instead of AOD to be consistent with the text.

the POM and CIMEL instruments' FOV is $\sim 1^{\circ}$. The difference between shadowband radiometer and sun-photometric retrievals of AOD has previously been observed, and subsequently empirically corrected for by di Sarra et al. (2015), 
Table 2. Correction values applied to AOD measured using Spectrometer 2. The correction factor is applied using Eq. (15).

\begin{tabular}{lrrrrr}
\hline Airmass & 1 & 2 & 3 & 6 & 10 \\
\hline OffsetA & 0.0097 & 0.0177 & -0.0033 & -0.0067 & -0.0117 \\
Wavelength (nm) & 440 & 500 & 675 & 870 & 1020 \\
OffsetW & 0.0244 & 0.026 & 0.0182 & 0.0124 & 0.0457 \\
SlopeW & 1.2701 & 1.2893 & 1.3549 & 1.4522 & 1.5237 \\
\hline
\end{tabular}

and attributed to the radiant impact of aerosol forward scattering on different instrumental FOVs. Here we investigate this further with a modelling study using the SMARTS2 (Gueymard, 2001) solar model. This has the facility for calculating the spectral $I_{\mathrm{N}}$ received for different aerosol conditions and different detector FOVs. The model was run for a range of different solar zenith angles $\left(0-85\right.$ with $10^{\circ}$ increments) and AODs (0.01-0.50 in 0.01 increments), and the $I_{\mathrm{N}}$ was calculated for a detector FOV of $7.5^{\circ}$, at $500 \mathrm{~nm}$. The AOD that would be calculated from the measured $I_{\mathrm{N}}$ using the spectrometer AOD Eqs. (1)-(8) was compared with the AOD value inputted into the model (Fig. 8). This shows two distinct features that aid in interpreting the intercomparison with the CIMEL (Fig. 7): (1) a regression slope of approximately 0.8 and (2) a slight dependency on solar zenith angle. Significantly, however, the over prediction of AOD at low atmospheric turbidities $(\mathrm{AOD}<0.1)$ is not reproduced. This behaviour can be replicated by introducing small calibration errors to the model data. At $500 \mathrm{~nm}$ the extra-terrestrial irradiance used in the SMARTS2 model is $1.932 \mathrm{Wm}^{-2} \mathrm{~nm}^{-1}$, but in the region between 495 and $505 \mathrm{~nm}$ (typical instrument bandwidth of $10 \mathrm{~nm})$ it varies between $2.059(497 \mathrm{~nm})$ and $1.878(502 \mathrm{~nm})$. This range of values can account for a variation in the retrieved $\mathrm{AOD}_{500}$ of approximately 0.08 . Not only does this highlight the importance of the accuracy of the instrument calibration, but also an understanding of instrument characteristics are required (spectral response function and resolution). At low optical depths, even in the most transparent atmospheric window, gaseous absorption is also likely to play a role in accurately determining AOD.

Using these insights from modelling, we are able to give a much closer correspondence to the Valencia CIMEL CE318 by (1) using the calibration transferred from the CIMEL CE318 for all values, rather than the original (Mt Teide) Langley calibration. The calibration adjustment for wavelength values between the CIMEL CE318 channel values is done using a linear interpolation, (2) applying a correction function for each CIMEL wavelength consisting of an offset related to solar zenith angle (air mass), and then a further linear transformation in AOD to give a true estimate of AOD as measured by the CIMEL CE318. The calculated correction factors (Table 2) are selected to give the best fit to the CIMEL CE318 AOD values and applied using an equation

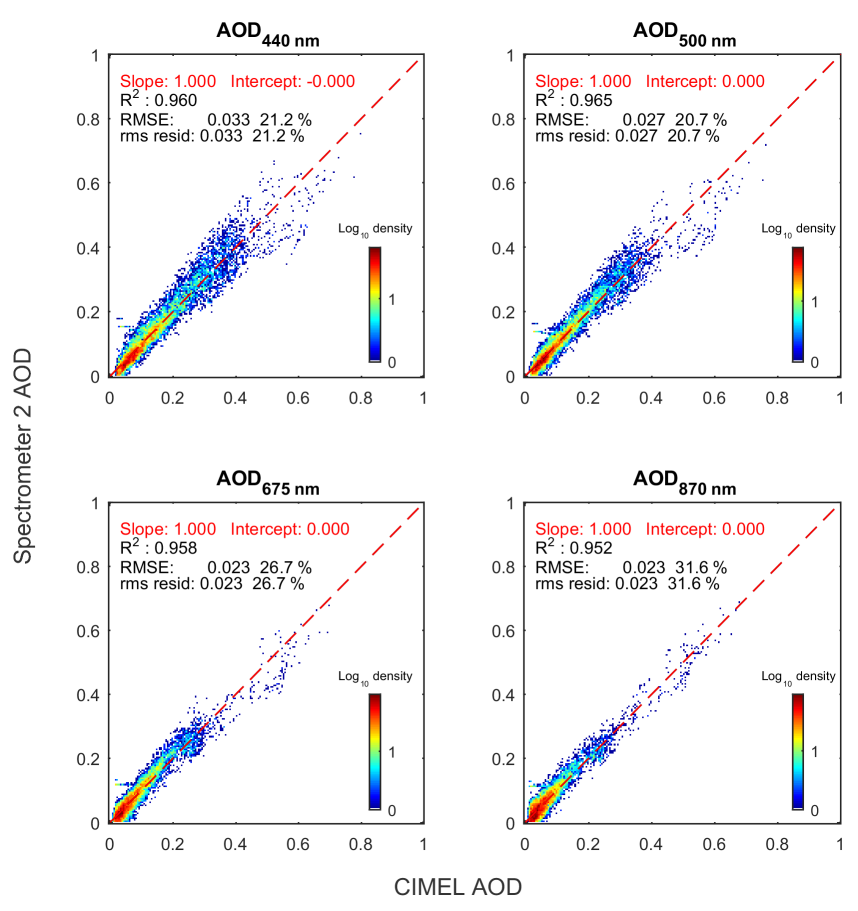

Figure 9. Corrected Zeiss AOD values compared with CIMEL sun photometer at Burjassot.

of the form

$$
\begin{aligned}
\operatorname{AOD}(\lambda)_{\text {corr }} & =\left(\operatorname{AOD}(\lambda)_{\text {meas }}-\operatorname{Offset} A(\text { airmass })\right. \\
& -\operatorname{Offset} \mathrm{W}(\lambda)) \times \operatorname{SlopeW}(\lambda) .
\end{aligned}
$$

These corrections show an RMSE of 0.02 to 0.03 when compared with the CIMEL CE318 (Fig. 9). While not perfect, this is approaching the uncertainty of AERONET fielddeployed CIMEL instruments (0.01-0.02) and the level of agreement between different sun photometers when they are compared together in the field (0.01-0.02) using different AOD methodologies (Estellés et al., 2006). LICOR 1800 spectroradiometers calibrated by lamps also have a nominal AOD uncertainty of about 0.02-0.05 (Estellés et al., 2006). These corrections were then applied to the Spectrometer 2 AOD results from the AMT cruise.

\subsection{Radiometric intercomparisons}

We configured the spectrometer operating software to routinely calculate four distinct datasets. The first is a daily time 
Table 3. Description and calibration details of instruments used in this paper.

\begin{tabular}{|c|c|c|c|c|}
\hline Instrument & Serial \# & Description & $\begin{array}{l}\text { Calibration dates and de- } \\
\text { tails }\end{array}$ & $\begin{array}{l}\text { Intercomparison dates and } \\
\text { details }\end{array}$ \\
\hline $\begin{array}{l}\text { Kipp \& Zonen } \\
\text { PQS } 1\end{array}$ & $\begin{array}{l}110126 \text { and } \\
110127\end{array}$ & $\begin{array}{l}\text { Kipp \& Zonen PAR sensors for } \\
400-700 \pm 4 \mathrm{~nm} \text { range situated on } \\
\text { RRS James Clark Ross instrument } \\
\text { platform. } \\
\text { FOV: } 180^{\circ} \text {; temperature response: } \\
<0.12 \% \mathrm{~K}^{-1} \text {; directional response: } \\
<0.03 \% \text { to } 80^{\circ} \text {; non-stability } \\
\text { (change/year): }<2 \% \text {. }\end{array}$ & $\begin{array}{l}\text { Kipp \& Zonen factory } \\
\text { calibration } \\
\text { standards } \\
*^{*} \text { Calibrationst known } \\
\text { every } 2 \text { years. }\end{array}$ & $\begin{array}{l}\text { 22/09/2014-01/11/2014; } \\
\text { AMT24 against calcu- } \\
\text { lated integrated PAR from } \\
\text { Spectrometer } 1 \text { and } 2 .\end{array}$ \\
\hline $\begin{array}{l}\text { Kipp \& Zonen SP- } \\
\text { Lite }\end{array}$ & $\begin{array}{l}112992 \& \\
112993\end{array}$ & $\begin{array}{l}\text { Kipp \& Zonen energy sensors for } 400- \\
1100 \mathrm{~nm} \text { range situated on RRS James } \\
\text { Clark Ross instrument platform. } \\
\text { FOV: } 180^{\circ} \text {; temperature response: } \\
<0.15 \% \mathrm{~K}^{-1} \text {; directional response: } \\
<5 \% \text { to } 80^{\circ} \text {; non-stability } \\
\text { (change/year): }<2 \% \text {. }\end{array}$ & $\begin{array}{l}\text { Kipp \& Zonen factory } \\
\text { calibration } 26 / 01 / 2011 . \\
{ }^{*} \text { Calibration recommended } \\
\text { every } 2 \text { years. }\end{array}$ & $\begin{array}{l}\text { 22/09/2014-01/11/2014; } \\
\text { AMT24 against calculated } \\
\text { integrated Energy from } \\
\text { Spectrometer } 1 \text { and } 2 .\end{array}$ \\
\hline $\begin{array}{l}\text { Satlantic hyper- } \\
\text { SAS hyperspectral } \\
\text { radiometer }\end{array}$ & SATHSE0258 & $\begin{array}{l}\text { Satlantic hyperspectral irradiance sen- } \\
\text { sor for } 305-1142 \mathrm{~nm} \text { range at } \sim 3 \\
\text { nm sampling resolution. Situated on } \\
\text { RRS James Clark Ross instrument } \\
\text { platform. } \\
\text { Directional response: } \\
3 \% \text { to } 60^{\circ}, 10 \% \text { to } 85^{\circ} \text {; spectral } \\
\text { resolution: } 10 \mathrm{~nm} \text {; spectral accuracy: } \\
0.3 \mathrm{~nm} \text {; } \\
\text { stray light }<10^{-3}\end{array}$ & $\begin{array}{l}\text { Satlantic factory calibra- } \\
\text { tion against known stan- } \\
\text { dards } 06 / 01 / 2014 \text {. }\end{array}$ & $\begin{array}{l}22 / 09 / 2014-01 / 11 / 2014 ; \\
\text { AMT24 against hyperspec- } \\
\text { tral data from Spectrometer } \\
1 \text { and } 2 .\end{array}$ \\
\hline Spectrometer 1 & AS161 & $\begin{array}{l}\text { See text for details. Situated on } \\
\text { RRS James Clark Ross instrument } \\
\text { platform. }\end{array}$ & $\begin{array}{l}\text { Laboratory calibration } \\
(02 / 10 / 2012) \text { at Winster; } \\
\text { Field calibration (Langley) } \\
(25 / 06 / 2014) \text { at Mt Teide. }\end{array}$ & $\begin{array}{l}\text { 14/07/2014-08/09/2014; } \\
\text { against POM-01 at } \\
\text { Plymouth PML. } \\
\text { 22/9/14-01/11/14; } \\
\text { AMT24 cruise. }\end{array}$ \\
\hline Spectrometer 2 & Zeiss & $\begin{array}{l}\text { See text for details. Situated on } \\
\text { RRS James Clark Ross instrument } \\
\text { platform. }\end{array}$ & $\begin{array}{l}\text { Laboratory calibration } \\
(11 / 03 / 2014) \text { at Winster; } \\
\text { field calibration (Langley) } \\
\text { (25/06/2014) at Mt Teide; } \\
\text { field calibration adjust- } \\
\text { ment at Burjassot against } \\
\text { CIMEL \#953 using } 11 \\
\text { clear-sky days, 17/05/2015 } \\
\text { to 01/06/2016. }\end{array}$ & $\begin{array}{l}\text { 22/9/14-01/11/14; } \\
\text { AMT24 cruise. } \\
\text { 29/01/2015-09/06/2016; } \\
\text { against CIMEL } 318 \\
\text { at Burjassot. }\end{array}$ \\
\hline SPN1 & A749 & $\begin{array}{l}\text { Delta-T broadband global \& diffuse } \\
\text { energy sensor. Situated on RRS James } \\
\text { Clark Ross instrument platform. } \\
\text { FOV: } 180^{\circ} \text {; temperature response: } \\
0.02 \% \mathrm{~K}^{-1} \text {; directional response: } 2 \% \text {; } \\
\text { non-linearity: <1\%; accuracy: } 8 \% \text { (to- } \\
\text { tal and diffuse). }\end{array}$ & $\begin{array}{l}\text { Field calibration at Me- } \\
\text { teoSwiss Payerne solar } \\
\text { measurement station, } \\
\text { June 2012-Sept 2013. } \\
\text { *Calibration recommended } \\
\text { every 2 years. }\end{array}$ & $\begin{array}{l}\text { 22/9/14-01/11/14; } \\
\text { AMT24 cruise. }\end{array}$ \\
\hline
\end{tabular}

series of the spectrally integrated values of global and diffuse irradiance (Fig. 10). This can be presented as either an integrated $\mathrm{Wm}^{-2}$ value across the full spectrum or weighted by wavelength to give, for example, PAR over the range 400$700 \mathrm{~nm}$. Other bands or weightings can be calculated from the raw data. The second is a daily time series of $\tau_{\mathrm{a}}$ at specific wavelengths chosen to match the output of other instruments such as the Microtops II or CIMEL CE318 sun photometer.
The third is the instantaneous $I_{\mathrm{G}}(\lambda)$ and $I_{\mathrm{D}}(\lambda)$ spectra for each measurement time (Fig. 11), and the fourth is the instantaneous $\tau_{\mathrm{a}}(\lambda)$ across the whole spectrum, outside of gaseous absorption bands, for each measurement time.

Comparisons of $1 \mathrm{~min}$ spectrally integrated data from the two spectrometers with the co-located SPN1 radiometer and Kipp \& Zonen PAR sensors (see Table 3 for instrument details) showed good agreement (Fig. 12). PAR measure- 


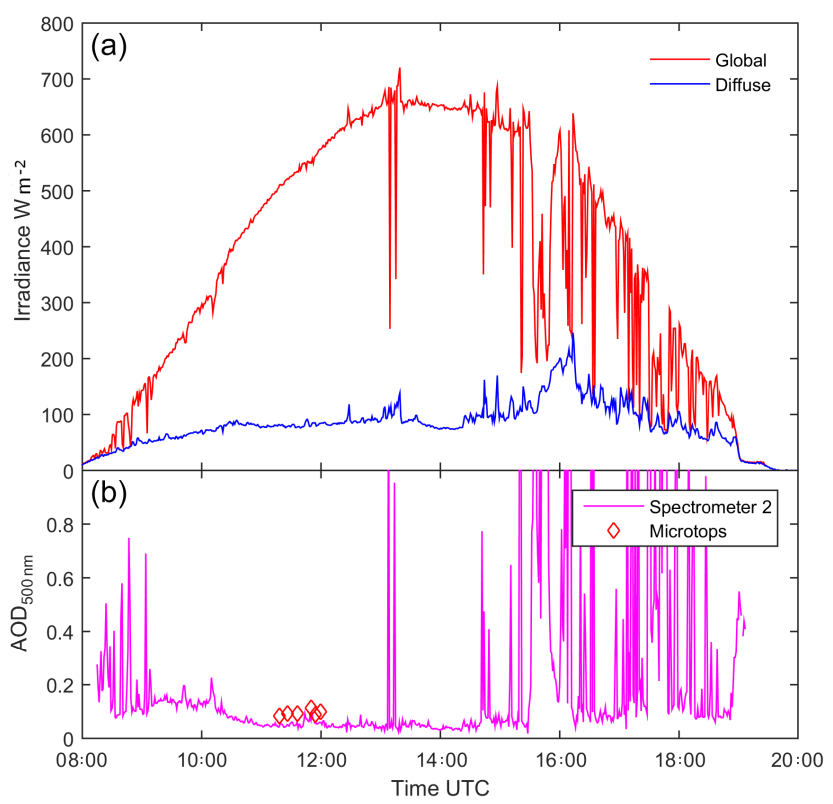

Figure 10. Time-series plots of integrated PAR values of $I_{\mathrm{G}}$ and $I_{\mathrm{D}}$ (a) and $\mathrm{AOD}_{500 \mathrm{~nm}}$ (b) for 4 October 2014. The Microtops $500 \mathrm{~nm}$ values are superimposed on the AOD plot. Cloud affected AOD have not been removed from the spectrometer database.

ments were $4 \%$ below and $0.6 \%$ above the Kipp \& Zonen PAR sensors respectively for the two spectrometers and $26 \%$ below the SPN1 radiometer. This latter difference is largely accounted for by the different spectral ranges measured, i.e. $380-1050 \mathrm{~nm}$ for the spectrometers, $400-2800 \mathrm{~nm}$ for the SPN1. Figure 13 shows an intercomparison with the co-located Satlantic HyperSAS hyperspectral radiometer (see Table 3 for instrument details). In the range 400$1050 \mathrm{~nm}$, Spectrometer 1 (AS161) agrees on average within $2.3 \%$ with the HyperSAS with a maximum difference of $0.05 \mathrm{Wm}^{-2} \mathrm{~nm}^{-1}$ at $752.5 \mathrm{~nm}$; Spectrometer 2 (Zeiss) is within $4.7 \%$ of the HyperSAS with a maximum difference of $0.025 \mathrm{Wm}^{-2} \mathrm{~nm}^{-1}$ at $927.1 \mathrm{~nm}$. Spectrometers 1 and 2 are within $2.2 \%$ of each other with a maximum difference of $0.07 \mathrm{Wm}^{-2} \mathrm{~nm}^{-1}$ at $754.0 \mathrm{~nm}$. Visually from Fig. 13, the largest inter-sensor differences occur within absorption bands, therefore different spectral resolutions may play a role in these regions.

\subsection{Corrected aerosol optical depth comparisons: AMT cruise}

During the AMT cruise, Microtops readings were taken when the sky was deemed sufficiently clear (clear view of the solar disc unobscured by clouds), and research schedules permitted time. Figure 14 shows these results plotted against latitude for the entire cruise for both Spectrometer 2 (Zeiss) and the Microtops (observations shown are single retrievals measured daily around solar noon if conditions allowed). The

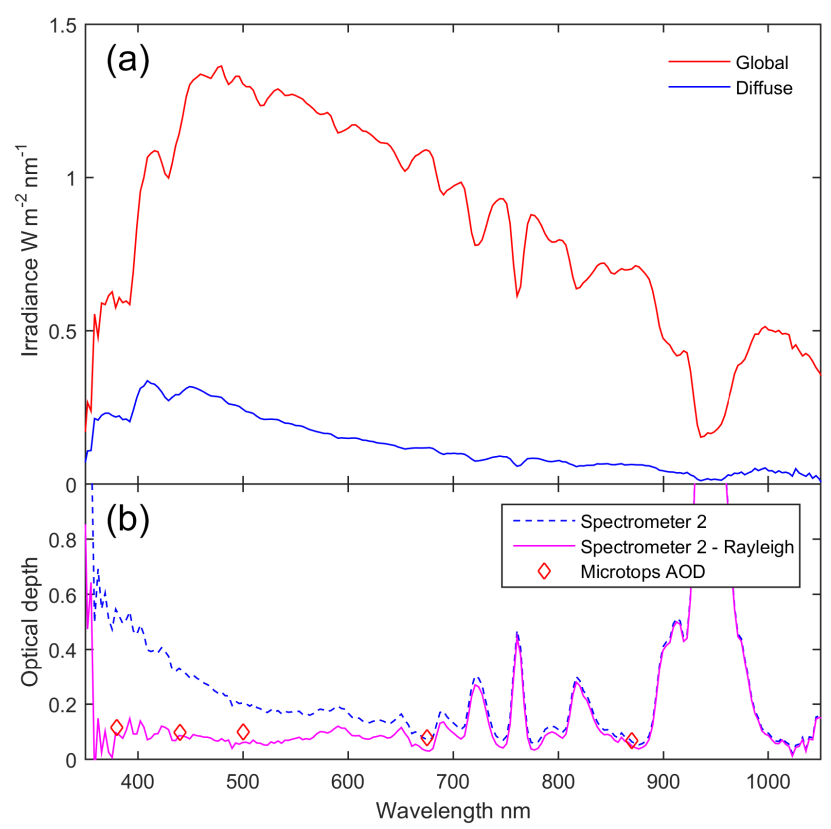

Figure 11. Spectrally resolved outputs for a single reading (12:00 on 4 October 2014). $I_{\mathrm{G}}$ and $I_{\mathrm{D}}$ spectra (a), and optical depth (b). Total optical depth (OD) and OD with the Rayleigh component removed are shown, with Microtops aerosol optical depth (AOD) values superimposed. Gaseous absorption features at certain windows have not been removed.

spectrometer results have been corrected for using the values determined using the 18-month intercomparison at the Burjassot site (Figs. 7 and 9 and Table 2). Background marine aerosol $\left(\mathrm{AOD}_{500 \mathrm{~nm}}<0.05\right)$ values are apparent in the region around $40^{\circ} \mathrm{N}$ and between 20 and $40^{\circ} \mathrm{S}$. Elevated values of AOD are clearly visible in locations associated with the Saharan dust plume $\left(20^{\circ} \mathrm{N}\right.$ : AOD $\left._{500 \mathrm{~nm}} \sim 0.5\right)$ and European anthropogenic pollution emitted by a combination of industrial and urban sources $\left(50^{\circ} \mathrm{N}\right.$ : $\left.\mathrm{AOD}_{500 \mathrm{~nm}} \sim 0.4\right)$. Comparisons between Spectrometer 2 (Zeiss) and Microtops at four different wavelengths (440, 500, 675 and $870 \mathrm{~nm}$ - Fig. 15) results in an RMSE between 0.04 and 0.05 , which is poorer than the results presented against the CIMEL (RMSE 0.03: Fig. 9), but the coefficient of determination $\left(R^{2}\right)$ remains high at around 0.95 for all wavelengths. Previous (unpublished) comparisons between Microtops and CIMEL CE318 resulted in an RMSE of between 0.01 and 0.02; an agreement to within $10 \%$ between Microtops, CIMEL and POM instruments has been reported in Poland under a variety of conditions (Evgenieva et al., 2008). However, the previous studies alluded to above have been for land-based observations and therefore no uncertainties due to the platform motion are present. Moreover, the Microtops AOD has a somewhat larger uncertainty than the CIMEL. 

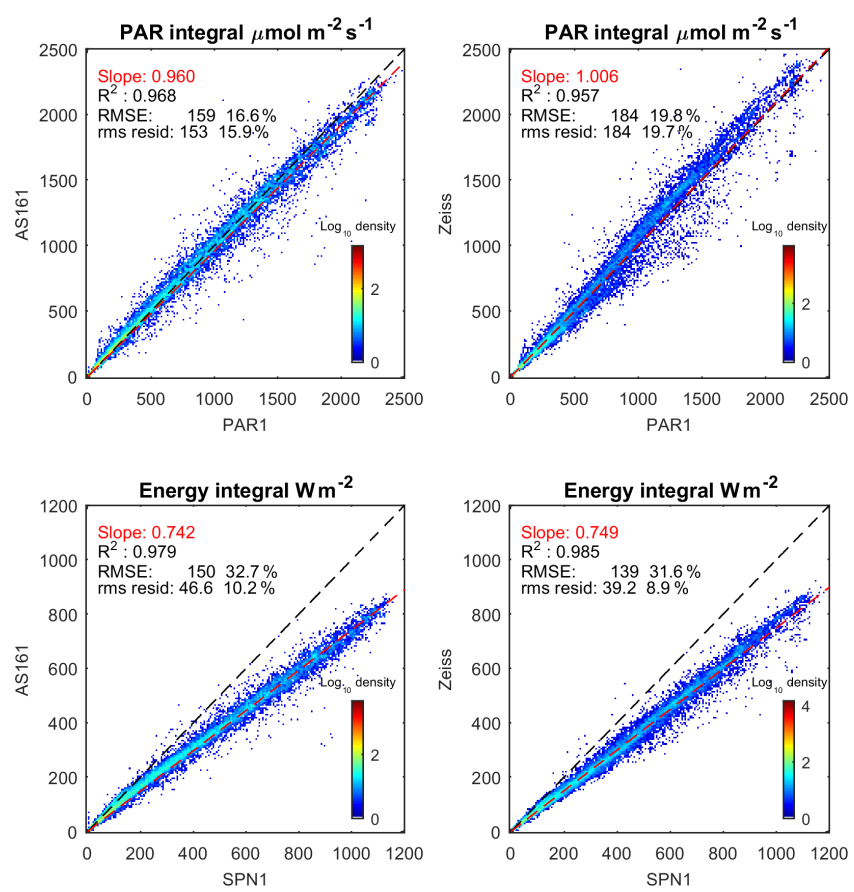

Figure 12. Comparisons of integrated PAR (400-700 nm, quantum weighting) and energy (integrated over 380-1050 nm) with the adjacent Kipp \& Zonen PQS-1 PAR sensor and SPN1.

\section{Discussion}

Overall the hyperspectral radiometers that we have developed gave excellent and robust performance in the field (terrestrial and marine) over protracted periods of deployment, with little or no operator intervention. The marine deployment in particular highlighted previously unforeseen practical issues. These were related to shading and soiling of the detector dome. While the instrument platform on the RRS James Clark Ross gave a reasonably good exposure to the sky, there was some shading possible, in particular, by two higher masts just forward of the spectrometers, containing the HyperSAS hyperspectral radiometer and an ultrasonic anemometer. The meteorological instrument solar radiation screens and the ship's main mast on the bridge could also obstruct the sun when close to the horizon. It was possible to identify and filter out many of these obstruction periods by comparing the outputs of adjacent sensors. In principle, it should also be possible to predict these occasions using a combination of the solar geometry, position and height of the masts relative to the instrument and the ship's attitude. However, this has not been done in this paper. There is always intense competition for the "top spot" on any ship, so some form of shading at times is always likely to be a problem.

Access to the instrument platform was restricted during the AMT24 cruise, so it was not possible to inspect or clean any of the instruments. The position of the mast towards the bow of the ship also brought it closer to birds slip-streaming the

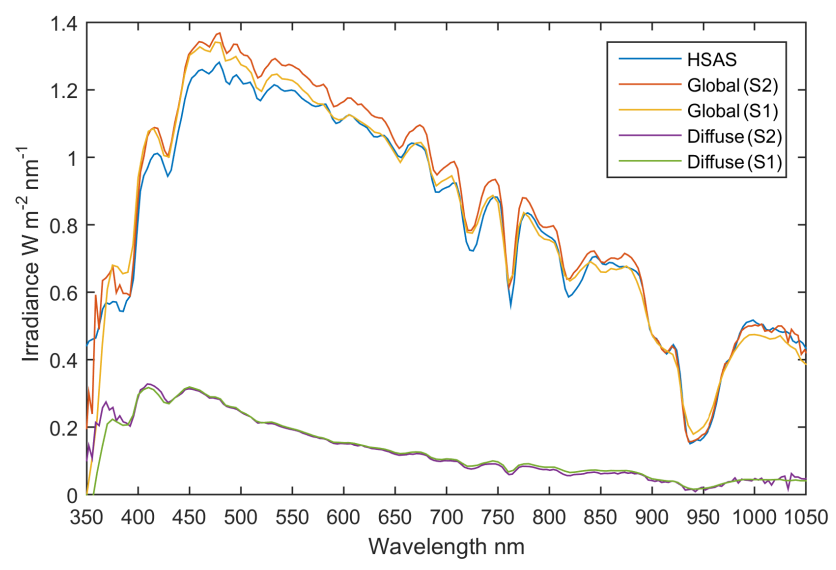

Figure 13. Spectral outputs $\left(I_{\mathrm{G}}\right.$ and $\left.I_{\mathrm{D}}\right)$ from the two spectrometers compared with the HyperSAS $I_{\mathrm{G}}$ at 12:00 on 4 October 2014.

forward air-pressure wave as well as providing a good position for perching. The instrument platform itself showed evidence of many direct hits from bird droppings, and there was white residue from fouling on the dome of Spectrometer 1 discovered upon instrument retrieval at the end of the cruise. This would have obviously caused degradation in the signal intensity and therefore, together with the electronics fault mentioned earlier in the text, the reason why data from Spectrometer 1 have not been analysed in depth and presented in this paper. Finding a position on the ship superstructure enabling a complete and unobstructed view of the sky as well as allowing access for periodic cleaning would almost certainly improve data quality. Multiple, season-long deployments (612 months) of the SPN1 on the Western Channel Observatory buoy at station L4 (Smyth et al., 2010) have shown the instrument to be remarkably resilient to such problems though, as it is always retrieved in a pristine condition. It is likely here that regular washing by rainwater keeps the dome free from fouling.

The storing and processing of the quantity of data produced by each spectrometer $\left(100 \mathrm{MB}\right.$ day $^{-1}$ Spectrometer 1 ; $30 \mathrm{MB}$ day $^{-1}$ Spectrometer 2 for 1 min readings) is a significant task. In order to report readings back via Iridium satellite communications, enabling full autonomy on ships of opportunity will either require a significant amount of data compression or a limited subset of measurements to be reported back. Full datasets, allowing in-depth analysis and quality control, will only be retrievable upon the completion of individual deployments. Therefore, further development is required to provide a balance between reporting derived quantities such as AOD and retaining the raw measurements to allow for further corrections or new products later.

The field intercomparisons of AOD carried out in this paper with existing multi-spectral instrumentation have necessarily been restricted to wavelengths at 400, 440, 500, 670 and $870 \mathrm{~nm}$. However, as both Spectrometer 1 and 2 are hyperspectral instruments, retrieval of hyperspectral AOD ob- 


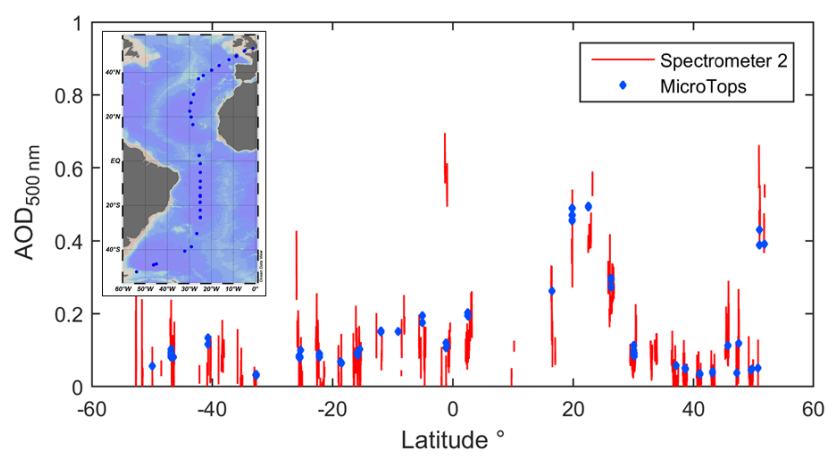

Figure 14. General evolution of $\mathrm{AOD}_{500 \mathrm{~nm}}$ as measured by Spectrometer 2 (Zeiss, red line) and Microtops (blue diamonds) over the duration of the AMT24 cruise. Map of the Microtops sampling locations shown in the upper left of figure.

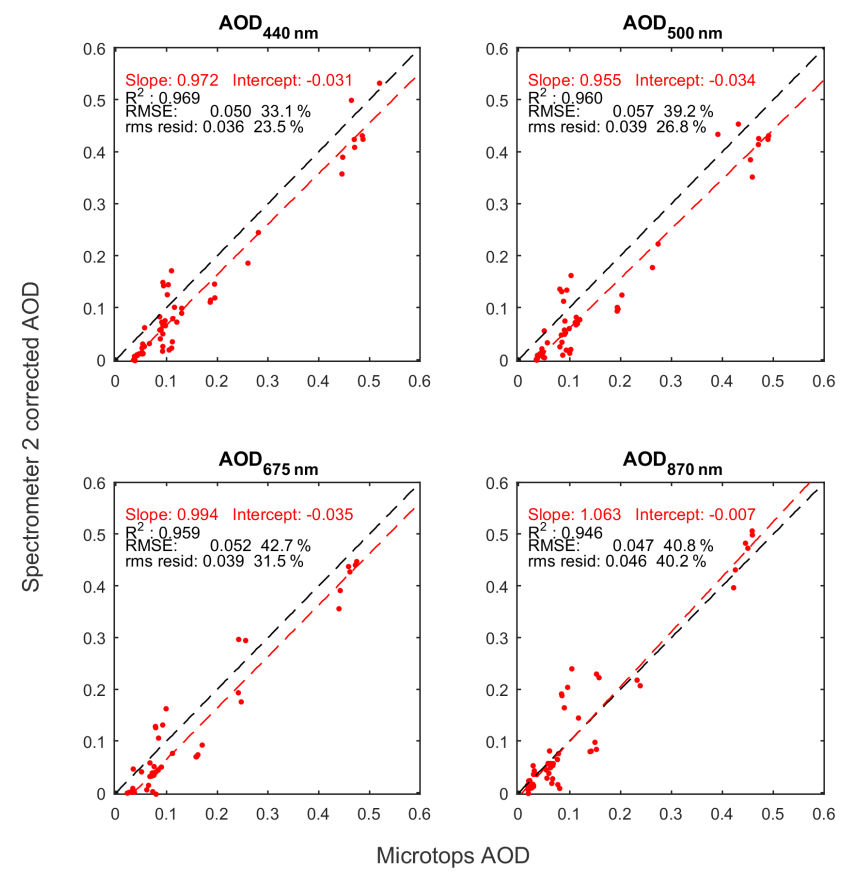

Figure 15. Comparison of Spectrometer 2 (Zeiss) and Microtops AOD measurements at four wavelengths over the AMT cruise.

servations are theoretically possible. To fully enable this, more work is required on the calibration of the instrument (where direct transferability between standard instruments is no longer possible) and correction for gaseous absorption (e.g. $\mathrm{NO}_{x}, \mathrm{O}_{2}$ and $\mathrm{H}_{2} \mathrm{O}$ absorption bands).

In this paper we have concentrated on the major sources of discrepancy between the different instrumentation (such as motion and FOV) and correcting the data for these effects using statistics or regressions. However, other sources of uncertainty are still inherent within the data and an analysis of, for example, temperature dependency, cosine response, response time and instrument attitude within the framework of an error propagation model (Miller et al., 2004) is required to fully understand the instrument characteristics. Uncertainties generated in the calibration procedure have been highlighted in this paper as an offset correction to the AOD calculation. It is also likely that there has been long-term instrument calibration drift during the period described in this paper, which has not been accounted for in our calculations. Some of the differences shown in Fig. 4 between the Mt Teide and Valencia Langley plots (separated by a period of 1-2 years; see Table 3) could be due to this factor, although there is an additional complication of inter-site differences (altitude, atmospheric composition). Calibration drift may also play a part in the comparison between the PAR and irradiant energy observations (Fig. 12) as a period of 4 years (recommended calibration interval is 2 years) separates the calibration points and the AMT24 cruise (Table 3). However, other sources of uncertainty exist in this case when comparing broadband with hyperspectral instrumentation, such as integration range, sensitivity and spectral response functions. The comparisons shown in Fig. 12 were intended to show that the hyperspectral instruments were capable of providing realistic retrievals of broadband quantities useful for marine environmental research. A more rigorous study of the accuracy and uncertainties of this spectrometer system will be the focus of future work.

Another limiting factor in this paper has been the timedimension. Handheld Microtops measurements are generally taken on an opportunistic footing, when a dedicated operator is not available; CIMEL and POM measurements are generally taken on a 10-15 min time interval. As observed by di Sarra et al. (2015), the shadowband-type technology can take readings on a sub-minute timescale, which allows almost continuous observations of AOD and the resolution of short-length and time-scale atmospheric aerosol features and variability. Although placing Spectrometer 1 and 2 on a ship, with many other sources of error such as motion and variable ship shading, may preclude accurate observation of such features, a land-based deployment should allow this opportunity.

\section{Conclusions}

The hyperspectral radiometer that we have developed and described in this paper has many advantages over the current generation of sun/sky radiometers. The system has the potential for operating remotely and autonomously for longperiods of time on ships of opportunity. As it has no moving parts, shade rings or motorised tracking, it lessens the number of points of failure which are particularly vulnerable in the marine environment (salt corrosion, freezing temperatures).

The fieldwork components of this study highlighted many issues which needed resolving. Some of these have been resolved, such as correcting for the motion of the ship; other issues such as characterisation and calibration have been partially resolved. The calibration issue is crucial, and the use 
of a Langley method as well as suitable periods of time using co-located instrumentation which are traceable to standards is required. This is standard within the existing networks such as AERONET (Holben et al., 1998). The development of a fully robust calibration protocol for the complete spectral range still requires development, together with a test of the correction (FOV and solar zenith angle) algorithms under a wider range of conditions than has been possible in this paper. The aerosol forward scatter (FOV difference) issue has been partially resolved using both theory and field measurements. However, the correction coefficients are likely to be specific to individual instruments. Overall, this paper has shown the technology that we have developed, together with its associated algorithms, to be a viable option when considering instrumentation for deployment on ships of opportunity in supporting and widening the global AERONET, SKYNET and ESR networks in the data sparse expanses of the ocean. The technology should also be transferrable to satellite calibration and validation studies, enabling the development of moveable fiducial points if deployed on, for example, an autonomous platform such as a wave glider.

Data availability. All data used in the generation of this paper is available on request from Tim J. Smyth.

Author contributions. John Wood built the two spectrometer systems described within this paper, carried out the calibrations and data analysis, and contributed to the writing of this paper. Tim J. Smyth took the two spectrometer systems on the AMT24 cruise and made all the ancillary measurements using the Microtops sun photometer, oversaw the Plymouth intercomparison fieldwork, undertook the modelling work and compiled the writing of this paper. Victor Estellés oversaw the Valencia intercomparison fieldwork and contributed to the writing of this paper.

Competing interests. The authors declare that they have no conflict of interest.

Acknowledgements. The authors would like to thank the crew of the RRS James Clark Ross and staff of the British Antarctic Survey for the considerable help they gave in deploying the spectrometers during AMT24. John Wood would like to thank Delta-T Devices Ltd for their encouragement and the East Midlands Development Agency for funding assistance during the early stage of prototype design. Victor Estellés was funded by the European Regional Development Fund, the Spanish Ministry of Economy and Competitiveness (CGL2015-64785-R, CGL2015-70432-R), and the Valencia Autonomous Government (PROMETEUII/2014/058). The Microtops data collected on AMT24 were processed by the NASA AERONET Maritime Aerosol Network program. This study is a contribution to the international IMBER project and was supported by the UK Natural Environment Research Council National Capability funding to Plymouth Marine Laboratory (Tim J. Smyth) and the National Oceanography Centre, Southampton. This is contribution number 307 of the AMT programme.

Edited by: M. Campanelli

Reviewed by: four anonymous referees

\section{References}

Adler-Golden, S. M. and Slusser, J. R.: Comparison of plotting methods for solar radiometer calibration, J. Atmos. Ocean. Technol., 24, 935-938, doi:10.1175/jtech2012.1, 2007.

Badosa, J., Wood, J., Blanc, P., Long, C. N., Vuilleumier, L., Demengel, D., and Haeffelin, M.: Solar irradiances measured using SPN1 radiometers: uncertainties and clues for development, Atmos. Meas. Tech., 7, 4267-4283, doi:10.5194/amt-7-4267-2014, 2014.

Baker, A. R., Jickells, T. D., Biswas, K. F., Weston, K., and French, M.: Nutrients in atmospheric aerosol particles along the Atlantic Meridional Transect, Deep-Sea Res. Pt.-II, 53, 1706-1719, doi:10.1016/j.dsr2.2006.05.012, 2006.

Campanelli, M., Estellés, V., Smyth, T., Tomasi, C., MartìnezLozano, M., Claxton, B., Muller, P., Pappalardo, G., Pietruczuk, A., and Shanklin, J.: Monitoring of Eyjafjallajökull volcanic aerosol by the new European Skynet Radiometers (ESR) network, Atmos. Environ., 48, 33-45, 2012.

Caquineau, S., Gaudichet, A., Gomes, L., and Legrand, M.: Mineralogy of Saharan dust transported over northwestern tropical Atlantic Ocean in relation to source regions, J. Geophys. Res.Atmos., 107, D15, doi:10.1029/2000jd000247, 2002.

di Sarra, A., Sferlazzo, D., Meloni, D., Anello, F., Bommarito, C., Corradini, S., De Silvestri, L., Di Iorio, T., Monteleone, F., Pace, G., Piacentino, S., and Pugnaghi, S.: Empirical correction of multifilter rotating shadowband radiometer (MFRSR) aerosol optical depths for the aerosol forward scattering and development of a long-term integrated MFRSR-Cimel dataset at Lampedusa, Appl. Opt., 54, 2725-2737, doi:10.1364/ao.54.002725, 2015.

Dubovik, O. and King, M. D.: A flexible inversion algorithm for retrieval of aerosol optical properties from Sun and sky radiance measurements, J. Geophys. Res.-Atmos., 105, 20673-20696, doi:10.1029/2000jd900282, 2000.

Estellés, V., Utrillas, M. P., Martinez-Lozano, J. A., Alcantara, A., Alados-Arboledas, L., Olmo, F. J., Lorente, J., de Cabo, X., Cachorro, V., Horvath, H., Labajo, A., Sorribas, M., Diaz, J. P., Diaz, A. M., Silva, A. M., Elias, T., Pujadas, M., Rodrigues, J. A., Canada, J., and Garcia, Y.: Intercomparison of spectroradiometers and Sun photometers for the determination of the aerosol optical depth during the VELETA-2002 field campaign, J. Geophys. Res.-Atmos., 111, D17, doi:10.1029/2005jd006047, 2006.

Estellés, V., Martinez-Lozano, J. A., Utrillas, M. P., and Campanelli, M.: Columnar aerosol properties in Valencia (Spain) by ground-based Sun photometry, J. Geophys. Res.-Atmos., 112, D11, doi:10.1029/2006jd008167, 2007.

Estellés, V., Smyth, T. J., and Campanelli, M.: Columnar aerosol properties in a Northeastern Atlantic site (Plymouth, United Kingdom) by means of ground based skyradiometer data during years 2000-2008, Atmos. Environ., 61, 180-188, doi:10.1016/j.atmosenv.2012.07.024, 2012. 
Evgenieva, T., Iliev, I., Kolev, N., Sobolewski, P., Pieterczuk, A., Holben, B., and Kolev, I.: Optical characteristics of aerosol determined by Cimel, Prede and Microtops II sun photometers over Belsk (Poland), in: 15th International School on Quantum Electronics: Laser Physics and Applications, edited by: Dreischuh, T., Taskova, E., Borisova, E., and Serafetinides, A., Proceedings of SPIE, 2008.

Gueymard, C. A.: Parameterized Transmittance Model for Direct Beam and Circumsolar Spectral Irradiance, Sol. Energ., 71, 325346, 2001

Guzzi, R., Maracci, G. C., Rizzi, R., and Siccardi, A.: Spectroradiometer for ground-based atmospheric measurements related to remote-sensing in the visible from a satellite, Appl. Opt., 24, 2859-2864, 1985.

Holben, B. N., Eck, T. F., Slutsker, I., Tanre, D., Buis, J. P., Setzer, A., Vermote, E., Reagan, J. A., Kaufman, Y. J., Nakajima, T., Lavenu, F., Jankowiak, I., and Smirnov, A.: AERONET - A federated instrument network and data archive for aerosol characterization, Remote Sens. Environ., 66, 1-16, doi:10.1016/s00344257(98)00031-5, 1998.

Kasten, F. and Young, A. T.: Revised optical air mass tables and approximation formula, Appl. Opt., 28, 4735-4738, 1989.

Lin, C. T., Jickells, T. D., Baker, A. R., Marca, A., and Johnson, M. T.: Aerosol isotopic ammonium signatures over the remote Atlantic Ocean, Atmos. Environ., 133, 165-169, doi:10.1016/j.atmosenv.2016.03.020, 2016.

Long, C. N., Bucholtz, A., Jonsson, H., Schmid, B., Vogelmann, A., and Wood, J.: A Method of Correcting for Tilt from Horizontal in Downwelling Shortwave Irradiance Measurements on Moving Platforms, The Open Atmospheric Science Journal, 4, 78-87, 2010.

McArthur, L. J. B.: World Climate Research Programme - Baseline Surface Radiation Network (BSRN) - Operations Manual Version 2.1, Downsview, Ontario, CANADA, Experimental Studies Division, Atmospheric Environment Service, 2005.

Miller, M. A., Bartholomew, M. J., and Reynolds, R. M.: The accuracy of marine shadow-band sun photometer measurements of aerosol optical thickness and Angstrom exponent, J. Atmos. Ocean. Technol., 21, 397-410, doi:10.1175/15200426(2004)021<0397:taomss>2.0.co;2, 2004.
Morys, M., Mims, F. M., Hagerup, S., Anderson, S. E., Baker, A., Kia, J., and Walkup, T.: Design, calibration, and performance of MICROTOPS II handheld ozone monitor and Sun photometer, J. Geophys. Res.-Atmos., 106, 14573-14582, doi:10.1029/2001jd900103, 2001.

Nakajima, T., Tonna, G., Rao, R., Boi, P., Kaufman, Y., and Holben, B.: Use of sky brightness measurements from ground for remote sensing of particulate polydispersions, Appl. Opt., 35, 2672-2686, 1996.

Reynolds, R. M., Miller, M. A., and Bartholomew, M. J.: Design, operation, and calibration of a shipboard fast-rotating shadowband spectral radiometer, J. Atmos. Ocean. Technol., 18, 200$214,2001$.

Smirnov, A., Holben, B. N., Slutsker, I., Giles, D. M., McClain, C. R., Eck, T. F., Sakerin, S. M., Macke, A., Croot, P., Zibordi, G., Quinn, P. K., Sciare, J., Kinne, S., Harvey, M., Smyth, T. J., Piketh, S., Zielinski, T., Proshutinsky, A., Goes, J. I., Nelson, N. B., Larouche, P., Radionov, V. F., Goloub, P., Moorthy, K. K., Matarrese, R., Robertson, E. J., and Jourdin, F.: Maritime Aerosol Network as a component of Aerosol Robotic Network, J. Geophys. Res.-Atmos., 114, D6, doi:10.1029/2008jd011257, 2009.

Smyth, T., Fishwick, J., Gallienne, C., Stephens, J., and Bale, A.: Technology, Design, and Operation of an Autonomous Buoy System in the Western English Channel, J. Atmos. Ocean. Technol., 27, 2056-2064, 2010.

Takamura, T. and Nakajima, T.: Overview of SKYNET and its activities, Opt. Pura Apl. , 37, 3303-3308, 2004.

Wood, J.: Solar Radiation Sensor, Patent: WO 99/13359, 26 pp., 1999. 